\title{
A DEMOCRACIA PARTICIPATIVA E SUA REALIZAÇÃO - PERSPECTIVA HISTÓRICA E PROSPECÇÃO FUTURA: O MARCO CIVIL PARAA REGULAMENTAÇÃO DA INTERNET NO BRASIL
}

\author{
MAKING PARTICIPATORY DEMOCRACY COME TRUE - HISTORICAL PERSPECTIVE AND FUTL RE \\ PROSPECTION: THE BRAZILIAN INTERNET REGULATORY FRAMEWORK
}

\section{Rubens Beçak \\ João Victor Rozatti Longh}

\begin{abstract}
Resumo:
São constantes os esforços para a consecução da democracia em sede global. A revolução das comunicações nos últimos anos trouxe consigo importantes meios para o exercício da liberdade de expressão e comunicação, direito fundamental de primeira geração, que toma feições cada dia mais globais e universais. Nessa esteira, afirma-se que os direitos humanos, hoje transnacionais e atinentes às gerações futuras, têm na democracia seu principal fundamento. É a democracia participativa, com a qual os cidadãos têm a sua inserção direta no jogo democrático assegurada. O presente trabalho procura analisar o caso do marco civil regulatório da Internet no Brasil, uma iniciativa pioneira, que explora as potencialidades da tecnologia para possibilitar ao cidadão a participação ativa na proposição da legislação sobre direitos e obrigações civis na Rede, capitaneada pela sociedade civil em conjunto com o Executivo. Essa é apenas uma das possibilidades de superação dos problemas atuais do sistema partidário nacional, carente de representatividade e fragilizado em legitimidade, risco ao próprio devir democrático.
\end{abstract}

Palavras-chave: Democracia participativa. Liberdade de expressão. Comunicação.

\begin{abstract}
:
Making democracy true is a will for everyone around the world. Nowadays, communications' revolution brought new artifacts for freedom of expression, a civil right that becomes global day-by-day. Therefore, democracy shapes up as fourth generation human right. It's the participatory democracy, in which the citizen directly acts in the democratic game. This article intends to investigate the brazilian Internet Regulatory Framework, a brand new civil society's joint initiative with the Executive that seeks to build a draft law about civil obligations and rights for national Internet actors. This is just an attempt to overcome the political party system, which passes through a lack of representativity and seems gently to lose legitimacy, a big risk for the survival of the democratic regime in the overcome.
\end{abstract}

Keywords: Participatory democracy. Freedom of expression. Communication.

Professor e Secretário Geral da Universidade de São Paulo. Doutor em Direito Constitucional pela Universidade de São Paulo.

*. Mestrando em Direito Civil pela UERJ. 
Introdução

Mesmo que esquecido no panorama nacional o debate acerca da Reforma Política, superado por outros mais pontuais, o questionamento sobre a democracia e sua expressão, subjacente àquele, permanece atual.

Entendemos, portanto, oportuna a discussão sobre o primado democrático e a reafirmação deste ideal, especialmente quando a discussão sobre o denominado marco civil para a regulamentação da Internet em nosso país está instalada.

Assim que, para se verificar a efetivação dos valores democráticos expressos na tríade liberdade, igualdade e fraternidade, isto somente se auferirá com o permear da própria ideia democrática por todos os setores da sociedade. E isto, em nosso entendimento, somente se faz com a democracia participativa.

Para tal fim, importante que a discussão sobre o tema se alastre e assim, uma evolução dos rumos da democracia, se faz necessária.

Com o ideal das idéias iluministas, advindo, no plano político, com a derrocada do regime absolutista, naquilo que Eric Hobsbawn consagrou como a era revolucionária, ${ }^{1}$ vai-se idealizar um sistema político adequado a dar sustentação à nova ordem.

A democracia dos gregos, no sentido daquela praticada especialmente no século de Péricles, em Atenas, será transplantada para os tempos contemporâneos havendo que incorporar instrumento sobrevindo do Direito Civil para sua viabilização, qual seja o mandato. É sem sombra de dúvidas com a representação, que os novos regimes praticarão a democracia, cognominada dali para a frente como indireta, ou representativa.

$\mathrm{Na}$ evolução da democracia, sabe-se que, se por um lado, a democracia representativa nasce com o viés da imperatividade da vontade do representado, no seu desenvolver, especialmente devido à sua evolução, exsurgirá a desvinculação. No tema, bastante trabalhado pela doutrina, Ferreira Filho pontua:

[...] A base fundamental da representação é a idéia exposta por Montesquieu de que os homens em geral não têm a necessária capacidade para bem apreciar e conseqüentemente bem decidir os problemas políticos. Assim, no interesse de todos, essas decisões devem ser confiadas aos mais capazes, aos representantes do povo. Mas todo e qualquer homem tem a capacidade de identificar, no seu círculo de convívio, esses que são mais capazes. Por isso, a seleção desses representantes deve ser dada a todo o povo, que a estabelecerá por meio de uma eleição (observese que, para a doutrina política helênica, a eleição era um

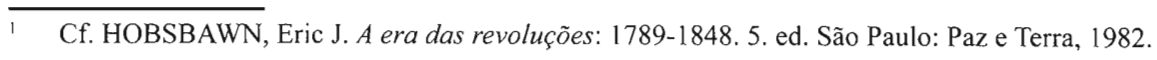


método aristocrático de seleção, enquanto o sorteio é que era considerado o modo democrático[...]. ${ }^{2}$

Edmund Burke, em seu famoso discurso aos eleitores de Bristol (1774), já pontuava no sentido da prevalência do "interesse nacional" por sobre o dos eleitores. Também a Constituição francesa de 1791 já o deixava claro: "os representantes nomeados nos departamentos não serão representantes de um determinado departamento, mas da nação inteira" 3

No momento seguinte de seu evolver, vai a democracia se defrontar com a questão da defesa de interesses por grupos mais ou menos fechados, os logo denominados partidos políticos, provocando o surgimento da democracia representativa pelos partidos. ${ }^{4}$

Entretanto, mormente já nas primeiras décadas do século $\mathrm{XX}$, ou mesmo antes, no final do século XIX, começa-se a perceber que aquele sistema - com a aparência de supra-sumo da evolução democrática - encontrava um questionamento sui-generis sobre em que medida não estaria a representação provocando distanciamento ou mesmo contrariando a vontade do representado, ${ }^{5}$ sobretudo considerada a existência desses novos partícipes da cena política: "À época, tinha-se a sensação de uma crise geral da representação política, regada com interpretações alarmadas atentando para os efeitos fatalmente corrosivos das novas instâncias de mediação - os partidos de massas - sobre o sistema clássico parlamentar" 6

Em um primeiro momento, a sedutora idéia da coexistência do modelo da representação tradicional com a de interesses cooperativos parecerá a solução. $\mathrm{O}$ instrumento foi utilizado por uma série de constituições européias, chegando ao Brasil, com a Constituição de 1934.

Entretanto, a ascensão avassaladora de uma nova forma de exercício do poder, o totalitarismo, logo fez colapsar a democracia como um todo, na exata medida em que esta era vista como um sistema decadente e distanciado da realidade.

Com o final da $2^{\text {a }}$ grande guerra, e a revalorização do poder da ideia democrática, logo não tardam também a ressurgir os críticos de suas eventuais falhas e inversão de valores. Agora, no entanto, as críticas não mais estarão centradas no ataque

2 FERREIRA FILHO, Manoel Gonçalves. Curso de direito constitucional. 34. ed., atual. São Paulo: Saraiva, 2008. p. 85. Cf. também, do mesmo autor, Aspectos do direito constitucional contemporâneo. 2. ed. São Paulo: Saraiva, 2009. p. 30.

3 LAVAlle, Adrián G.; HOUTZAGer, Peter P.; CASTEllo, Graziela. Democracia, pluralização da representação e sociedade civil. Lua Nova: revista de cultura e política, São Paulo, n. 67, p. 54-55, 2006. (O futuro da representação).

4 FERREIRA FILHO, Manoel Gonçalves. Curso... cit., p. 88 e ss.

5 Id. Ibid., p. 93.

6 LAVAlLE, Adrián G.; HOUTZAGER, Peter P.; CASTELLO, Graziela. op. cit., p. 67. 
à democracia em si, mas sim na busca de instrumentos novos que possibilitassem o seu repensar, o seu aprimoramento.

Joseph Schumpeter, já advertia nos anos 40 sobre o fato de os candidatos (aos cargos eletivos) proporem “políticas para se (re) eleger em vez de serem eleitos para realizar políticas definidas pela população (...)" ?

A democracia participativa

Manoel Gonçalves Ferreira Filho, foi um dos primeiros a apontar a resiliência desta crítica, ${ }^{8}$ demonstrando o surgimento de nova forma da democracia, a democracia semi-direta.

Trata-se da tradicional democracia representativa, não abdicando da presença dos partidos políticos, acrescida da instrumentalização de institutos que possam servir à que se aufira a vontade do povo quando necessário. Isto, no intuito de diminuir aquele gap já mencionado, de efetivação da vontade do representado.

$O$ instrumento por excelência de sua viabilização é o plebiscito, mas não esqueçamos também aqueles outros previstos na atual Constituição Brasileira, como o referendum e a iniciativa popular, além de outros, que abordaremos.

$\mathrm{O}$ plebiscito tem origem no direito romano, sendo instituto largamente adotado mundo afora.

A história registra uma variante de sua utilização, sempre vista com reservas pelos seus críticos, mormente o seu viés porventura antidemocrático, a chamada "democracia cesarista" 9

Veja-se a sua utilização como instrumento real de aferição da verdade popular, como o foi aquele de 1993, em nosso país, que definiu a forma e o regime de governo.

No tocante, além do que consta do art. 14, I, da Constituição Federal, onde aparece para a realização da soberania popular, é também e especialmente - mecanismo necessário para a criação, incorporação, fusão e desmembramento de municípios (art. 18, $\left.\S 4^{\circ}\right)$ e estados $\left(\S 3^{\circ}\right.$ do mesmo artigo).

7 SCHUMPETER, Joseph A. apud LAVALLE, Adrián G.; HOUTZAGER, Peter P.; CASTELlO, Graziela. Democracia, pluralização da representação e sociedade civil. Lua Nova: revista de cultura e política, São Paulo, n. 67, p. 54-55, 2006. p. 59.

8 FERREIRA FILHO, Manoel Gonçalves. Curso... cit., p. 97.

9 Napoleão, Napoleão III e outros a utilizaram, e não nos esqueçamos de tiranos mais recentes, como Pinochet no Chile, no final dos anos 80 e inícios dos 90, para tentar revestir de legitimidade decisões de governo. Também aqueles entendidos como democratas. De Gaulle utilizou o instituto à exaustão, inclusive tendo renunciado à Presidência da França, em 1969, quando derrotado numa dessas consultas. A utilização exagerada, ou "desvirtuada", do instrumento sempre sofreu críticas: o mecanismo em si, não. 
O referendo, ou melhor, denominado referendum, em latim, para diferenciálo da expressão por vezes utilizada para exercício do voto, nada mais é do que a possibilidade da própria aprovação (ou rejeição) de um projeto de lei diretamente pela população.

Duas observações se fazem necessárias: a primeira é que existem sistemas onde se permite inclusive a alteração eventual de projeto de lei pela população (consultas em referendum, putativas), como é exemplo a Itália e, a segunda, que na prática constitucional brasileira parece comum i.e. a confusão deste instituto com o plebiscito, não só midiaticamente como também por parte da Administração (como foi exemplo o plebiscito de Janeiro de 1963, sobre o sistema de governo, que na realidade foi referendum).

Quem bem conceitua as diferenças entre dois institutos é o mais uma vez lembrado Manoel Gonçalves Ferreira Filho, ${ }^{10}$ demonstrando, inclusive, a possibilidade de o referendum ser formulado enquanto exercício do poder constituinte pelo povo. É instrumento previsto na Constituição Federal, no art. 14, II.

No nosso sistema constitucional, é o Congresso Nacional que exerce o poder de convocar o plebiscito e de autorizar o referendo (art. 49, XV).

Por derradeiro, a iniciativa popular. Este é instrumento previsto na Constituição Federal, no inciso III do art. 14 e também no art. $27, \S 3^{\circ}$, no que se refere à iniciativa popular no processo legislativo estadual. Sua regulação vem no art. $61, \S 2^{\circ}$ onde encontramos os requisitos ${ }^{11}$ que, pela dificuldade de efetivação, já configuram por si mesmos o seu "sepultamento":

Art. $61, \S 2^{\circ} \mathrm{A}$ iniciativa popular pode ser exercida pela apresentação à Câmara dos Deputados de projeto de lei submetido por, no mínimo, um por cento do eleitorado nacional, distribuído pelo menos por 5 Estados, com não menos de 3 décimos por cento dos eleitores de cada 1 deles.

Ora, no dizer de Sérgio Resende de Barros, ${ }^{12}$ segue sendo mais fácil (e "econômico") deslocar-se por avião até Brasília e realizar pressão por sobre os deputados de sua região pessoalmente ou até mesmo nas vindas semanais destes aos seus estados de origem - do que cumprir os requisitos constitucionais...

Não nos esqueçamos que a doutrina tradicionalmente elenca outros meios de exercício da democracia participativa, especialmente no direito norte-americano.

FERREIRA FILHO, Manoel Gonçalves. Curso... cit., 98.

1 Sobre a iniciativa popular e seus requisitos cf. SILVA, José Afonso da. Comentário contextual a Constituição. 3. ed. São Paulo: Malheiros, 2007. p. 223-224 e 449-450.

12 BARROS, Sérgio Resende de. In: Aulas proferidas no curso de graduação em Direito, na Faculdade de Direito da USP, compartilhadas com o Autor, nos anos de 2002-2003. 
Outros instrumentos de realização da democracia participativa

Ali temos os chamados veto popular, aonde uma lei em vigor pode ir a escrutínio popular se houver solicitação de certo número de eleitores.

Ainda o recall ou revocação, em que, igualmente por solicitação dos eleitores, o que vai a escrutínio popular é o mandato de parlamentar ou funcionário eleito (lembremos que nos EUA parte das funções judiciais e que outras, são eletivos).

José Afonso da Silva relaciona ${ }^{13}$ a Ação Popular, dentre nós desde a Constituição de 1934, como efetivo exercício de participação na vida política. Nós nos aventuramos ainda a dizer que a Ação Civil Pública, existente infraconstitucionalmente ${ }^{14}$ desde 1985, constitucionalizada em 1988, também é - por via reflexa - instrumento para tal.

Mas será que com esta descrição do instrumental mais usualmente colocado à disposição do cidadão, temos realmente uma gama de mecanismos que permitam que se supra aquele distanciamento a que já nos referimos, aquela sensação que é de certa forma comum, de que as reais necessidades e angústias da população não estão sendo discutidas nos foros de exercício do poder? Como aprimorar isto?

É aqui que uma série de estudos tem-se produzido, inclusive algumas experiências se praticado, também em nosso país, no sentido de diminuir esta distância.

Vejam-se os estudos pioneiros de Capeletti acerca da utilização da televisão como forma de aproximação, papel que hoje em dia poderia perfeitamente caber à Internet, como, aliás, é a proposta concreta do ex-Vice-Presidente norte-americano Al Gore, no seu The Assault on Reason. ${ }^{15}$

Paulo Bonavides já advogou a possibilidade de elaboração de Emenda Constitucional popularmente, pela inclusão de item IV ao art. 60 da Constituição. ${ }^{16}$

Propostas há de criação do mandato imperativo, não no sentido antigo de sua utilização, mas no da vinculação da ação do parlamentar ao programa partidário ou de governo, sob pena de revocação de seu mandato.

Não nos olvidemos também de algumas experiências efetivamente colocadas em prática, como o orçamento participativo, algo que de forma pioneira surgiu no Rio Grande do Sul e de lá espalhou-se, sendo hoje, conforme preleção de Boaventura de Souza Santos, ${ }^{17}$ utilizado em mais de 1.200 cidades da América Latina.

\footnotetext{
13 SILVA, José Afonso da. Poder constituinte e poder popular: estudos sobre a Constituição. São Paulo, Malheiros, 2000. p. 50-51.

$14 \quad$ Lei n. 7.347/85.

15 GORE, Al. The Assault on Reason. USA: Penguin Press, 2007.

16 BONAVIDES, Paulo. Constituinte e Iniciativa Popular. Folha de São Paulo, São Paulo, 9 de Julho de 2007.

17 SANTOS, Boaventura de Souza. In: Joint Annual Meeting of the Law and Society Association (LSA) and the Research Committee on Sociology of Law (RCSL)., Berlim, 25 a 28 de Julho de 2007.
} 
Importante ainda referirmos os Conselhos Municipais de Saúde, também citados por aquele estudioso. E os Conselhos Escolares, de Segurança, de gestão de espaços públicos etc., todos eleitos pela população.

Obviamente estas vias de participação democrática encontram uma grande resistência dos partidos políticos, que as vêem como verdadeira ameaça.

Em todas estas experiências e ou sugestões torna-se evidente a retomada dos valores rousseauneanos inclusive na sua crítica aos institutos (tradicionais) da representação.

Concordamos com Roberto Amaral, ${ }^{18}$ que, invocando seguidores da teoria rousseauneana no aspecto, como Marx, Gramsci, Lukács, Bobbio e Poulantzas, vê a representação como desvirtuadora da vontade soberana.

Do outro lado do espectro ideológico, também a crítica é acerba!

Joseph Schumpeter (tão revalorizado nos dias de hoje) e Hanna Arendt são exemplos: Para o primeiro: “(...) [é um] método de seleção das elites através de eleições periódicas (...)"19 ou, para a segunda: "(..) o que agora chamamos democracia é uma forma de governo na qual poucos governam em nome do interesse da maioria (...)"20

Aqui, cabe-nos uma breve referência do que se passa na Venezuela,e que também foi discutido nos últimos processos constituintes do continente, a saber, o equatoriano e o boliviano.

$\mathrm{Na}$ Venezuela, a Constituição Bolivariana de 1999, contém mecanismos participativos arrolados no seu art. $70 .^{21}$

O que se nota é que o caminho da participação como forma de aperfeiçoamento democrático parece ser algo irreversível, o que a sua adoção por um número cada vez maior de países parece indicar.

Por derradeiro, cabe ainda uma ponderação no que respeita ao papel da participação também como elemento de maximização da democracia deliberativa, no sentido dela não ser vista mais como inoperante na consecução constitucional. Isto porquê muitos daqueles que defendem o fenômeno do ativismo judiciário, depositam ali suas esperanças de realização do primado constitucional, muitas vezes vêm a se decepcionar com a efetiva manifestação judicial, ou ainda, no dizer de Cláudio Pereira de Souza Neto, ${ }^{22}$

\footnotetext{
18 Cf. AMARAL, Roberto. Apontamentos para a reforma política: a democracia representativa está morta; viva a democracia participativa. Revista de Informação Legislativa, Brasília, n. 151. jul./set. 2001. Brasília, 2001.

19 SCHUMPETER, Joseph A. apud AMARAL, Roberto. op. cit. p.32.

20 ARENDT, Hanna. apud AMARAL, Roberto. Id. p. 32.

21 “(...) I- instrumentos políticos: a. a eleição para o exercício de cargos públicos; b. o referendo; c. a consulta popular; d. a assembléia aberta, e; e. a assembléia dos cidadãos, cujas decisões têm caráter vinculante. II- instrumentos sociais e econômicos: a. a autogestão; b. a co-gestão; c. as cooperativas, em todas as suas formas, inclusive as de caráter financeiro; $d$. as caixas de poupança; e. a empresa comunitária. O referendo poderá ser consultivo, confirmatório ou revogatório. [...]"

22 SOUZA NETO, Cláudio Pereira de. Teoria constitucional e democracia deliberativa: um estudo sobre o
} 
com a possível crítica de a sobrecarga no Judiciário configurar eventual transferência do pólo decisório à elites. Confira-se o autor citado:

Para a perspectiva democrático-deliberativa, a solução para os problemas da democracia não pode ser senão o aprofundamento das próprias práticas democráticas, e não a transferência do poder decisório a elites sejam econômicas ou culturais. No entanto, essa ressalva não significa que a democracia deliberativa deixe de atribuir ao Judiciário um papel fundamental no regime democrático. ${ }^{23}$

A democracia participativa e os direitos fundamentais

"Todos os seres humanos nascem livres e iguais em dignidade e direitos."24 É o que proclama em primeiro plano a Declaração dos Direitos Humanos da ONU. A afirmação da liberdade, enquanto fundamento para a construção dos direitos fundamentais de primeira geração, é tida como a alma do constitucionalismo e das revoluções liberais já no século XIX, culminando na positivação das liberdades públicas em sede constitucional.

Em linhas gerais, o que se sabe é que a proclamação da liberdade e igualdade dos cidadãos como limitação ao poder do Estado, até então monárquico e absolutista, não se sustenta por si só durante muito tempo. Afinal, processos sociais como a urbanização e o desenvolvimento de uma sociedade industrial introduzem novos interesses políticos, os quais, quando contrapostos dialeticamente, criam demandas ao Estado que exigiram sua atuação positiva. Surgem então os direitos sociais ou direitos fundamentais de segunda geração.

Hoje, já se encontram claramente positivados direitos fundamentais de terceira geração, como aqueles difusos e coletivos, havendo até quem já mencione os direitos de quarta geração, representados pela proteção da biodiversidade, dentre outras matérias. ${ }^{25} \mathrm{O}$ fato é que, em se tratando de direitos fundamentais, não haja sobreposição e substituição, mas sim cumulatividade e convivência harmônica das conquistas aquiescidas e positivadas em cada momento histórico. ${ }^{26}$

papel do direito na garantia das condições para a cooperação na deliberação democrática. Rio de Janeiro: Renovar, 2006. p. 302.

23 Id. Ibid., p. 302.

24 ORGANIZAÇÃO DAS NAÇÕES UNIDAS. Declaração Universal dos Direitos Humanos. Art. $1^{\circ}$, primeira parte.

25 Nesse sentido V. ALVES, Eliana Calmon. Direitos de quarta geração: biodiversidade e biopirataria. Revista do Tribunal Regional do Trabalho da $5^{a}$ Região, v. 4, n. 1, p.41-61, dez. 2002. passim.

26 É o que conclui Paulo Gustavo Gonet Branco: “A visão dos direitos fundamentais em termos de gerações indica o caráter cumulativo da evolução desses direitos no tempo. Não se deve deixar de situar todos os direitos nem contexto de unidade e indivisibilidade. Cada direito de cada geração interage com os das outras e, nesse processo, dá-se à compreensão." MENDES, Gilmar Ferreira; COELHO, Inocêncio Mártires; BRANCO, Paulo Gustavo Gonet. Curso de direito constitucional. São Paulo: Saraiva, 2009. p. 268. 
Entretanto, entre positivação e efetivação há um longo caminho a ser percorrido, cujas tortuosidades, ademais, não param de surgir. Os desafios impostos pela massificação das novas tecnologias trouxeram drásticas transformações à ciência jurídica contemporânea. A nova realidade dos meios de comunicação, por exemplo, faz com que o sistema jurídico defronte-se com novas formas de violação dos direitos fundamentais até mesmo pelo próprio Estado, pondo por terra as edificações jurídicas, fruto das conquistas políticas aquiescidas até então.

$\mathrm{E}$ se vai mais além. Afirma-se que a própria democracia, conforme concebida e instrumentalizada nos formatos das repúblicas constitucionais modernas vive um momento de esgotamento por insuficiência. A democracia representativa e as formas constitucionalizadas de exercício da democracia direta são postas em cheque quando dependem necessariamente da esvaziada política partidária para a criação. Constata-o também Joaquim Falcão:

Nunca no mundo tantos países adotaram a democracia representativa. [...]. Mas, sabemos todos, que nova Constituição, separação dos poderes, eleições gerais e rotatividade no poder é apenas o começo e não o fim. $\mathrm{O}$ fato de países serem formalmente democráticos não os transforma em países de cidadãos participantes livres e iguais. ${ }^{27}$

1. Liberdades de expressão e de informação na teoria dos direitos humanos

A positivação da liberdade de expressão constitui uma conquista já da primeira era de direitos fundamentais. Afirma-se costumeiramente que a Inglaterra foi o primeiro a consagrá-lo, no "Licensing Act" de 1695. Outros países como França e Estados Unidos o fizeram anos mais tarde. Hoje, está contida na Declaração de Direitos Humanos da ONU (art. XIX ${ }^{28}$ ), assim como nos Convênios de Roma (art. $10^{\circ}$ ) e no Pacto de San José da Costa Rica (art. 13 $\left.{ }^{\circ}\right)^{29}$

$\mathrm{Na}$ Constituição brasileira, são fartas as menções ao respectivo direito fundamental e seus corolários. Destacam-se, no art. $5^{\circ}$, os incisos IV, IX e XIV, além dos $\S \S 1^{\circ}$ e $2^{\circ}$ do art. 220. No Direito estrangeiro, muitas Constituições também o fazem, v.g., as Constituições espanhola (art. 20.1), portuguesa (art. 37.1), dentre tantas outras.

27 FALCÃO, Joaquim. Democracia, direito e terceiro setor. 2. ed. Rio de Janeiro: FGV, 2006. p. 52.

28 Artigo XIX. Todo ser humano tem direito à liberdade de opinião e expressão; este direito inclui a liberdade de, sem interferência, ter opiniões e de procurar, receber e transmitir informações e idéias por quaisquer meios e independentemente de fronteiras.

29 Cf. FARIAS, Edilsom Pereira de. Colisão de direitos: a honra, a intimidade, a vida privada e a imagem versus a liberdade de expressão e comunicação. 3. ed. rev. e atual. Porto Alegre: Sergio Antonio Fabris, 2008. 143-145. 
Peter Häberle leciona que as chamadas "liberdades de comunicação" por ele compreendidas "no sentido mais amplo possível", abrangendo as liberdades de credo, artística e científica, de opinião e até mesmo reunião e associação, constituem não só uma ponte entre a dignidade humana e a democracia, no que tange ao binômio indivíduo-Estado, "mas possibilitam também a vida de esferas parciais da assim chamada 'sociedade', que muitos preferem chamar de "sociedade civil" (civil society). Conclui: "Mas no tema aqui discutido [o nexo interno entre democracia pluralista e dignidade humana] importa apenas reconhecer na liberdade de comunicação o cerne da democracia pluralista fundamentada na dignidade humana" 30

Por seu turno, outros distinguem as liberdades de expressão e de informação ou comunicação. ${ }^{31}$ A chamada concepção dualista fora consagrada pelo Tribunal Europeu de Direitos Humanos, tese também aceita em muitos julgados do Tribunal Constitucional Espanhol. Uma vez que a Constituição hispana e a Carta Européia adotam a concepção monista, ganha relevância como um dos critérios de ponderação utilizados pela corte para se aferir a sobreposição, no caso concreto, da liberdade de informação (e não de expressão) quando em colisão com o direito à honra objetiva (honor). ${ }^{32}$

Embora relevante a distinção para a ponderação, no caso concreto, com outros direitos fundamentais, seu fundamento é o mesmo. Posto isto, convém avançarmos na análise do fundamento dos direitos humanos na atualidade, o princípio da dignidade da pessoa humana em suas múltiplas expressões, tal como sua intrínseca relação com o regime democrático hoje adotado pela maioria dos países, ainda que longe de ser efetivado.

30 HÄBERLE, Peter. A dignidade humana e a democracia pluralista - seu nexo interno. In: SARLET, Ingo Wolfgang (Org.). Direitos fundamentais, informática e comunicação: algumas aproximações. Porto Alegre: livraria do advogado, 2007. p. 24-26

31 Acerca da delimitação terminológica, Edilsom Pereira de Farias decidiu por substituir a expressão "liberdade de informação", de origem francesa e empregada nos diplomas estrangeiros e nos tratados internacionais de direitos humanos, pela locução "liberdade de comunicação" Justifica: "A rigor a frase liberdade de informação, [...], não se afigura a mais apropriada para denominar o processo da comunicação. O termo comunicação, e não o termo informação, é o que "etimologicamente expressa a idéia de transmitir algo a alguém, ou seja, compartilhar com outrem algo de que se dispõe" O vocábulo informação é adequado para designar um conteúdo possível do processo comunicativo. Em suma, a informação é objeto da comunicação." FARIAS, Edilsom Pereira de. $O b$. cit. p. 142. Suas conclusões, ademais, ganham força quando analisadas em conjunto com as de Ciro Marcondes Filho, quem, ao examinar postulados da obra de Niklas Luhmann, afirma que: "[...] nós até agora interpretamos equivocadamente a informação. As antigas teorias afirmam que 'comunicar é transferir a informação', quando na realidade diz Luhmann, comunicar não é se desfazer de nada, é, antes, um processo multiplicador." MARCONDES FILHO, Ciro. Prefácio à obra LUHMANN, Niklas. A realidade dos meios de comunicação. Tradução Ciro Marcondes Filho. São Paulo: Editora Paulus, 2005. p. 7. A distinção terá importantes reflexos no sistema jurídico à medida que os meios de comunicação ganham importância cada vez crescente em nossa sociedade, incluso como perpetuadores das relações opressivas de poder, alterando drasticamente os limites da liberdade de comunicação em colisão com outros direitos fundamentais que, em igual medida, expressam elementos da dignidade por se referirem a valores da personalidade (honra, privacidade, proteção dos dados pessoais, etc.).

32 Cf. GUTIÉRREZ. David Ortega. Derecho a la información versus Derecho al honor. Madrid: Centro de estudos constitucionales, 1999. p. 118. 
2. Fundamento dos direitos humanos: a dignidade da pessoa humana

Inserida a liberdade de se comunicar, em sentido lato, no rol dos direitos humanos, mister avançarmos para a determinação de seu fundamento, qual seja o princípio fundamental da dignidade da pessoa humana.

Conforme se sabe, o momento histórico que fez com que a ciência jurídica, mormente por meio da teoria dos direitos fundamentais e da teoria da justiça, reaproximassese de uma fundamentação axiológica para a compreensão dos institutos jurídicos foi a segunda grande guerra, no fim da primeira metade do século XX. Dessa maneira, procurou-se superar os postulados do positivismo jurídico, vertendo-se a discussão acerca da fundamentação moral do Direito, evitando-se os problemas decorrentes da aplicação desmedida dos postulados positivistas. ${ }^{33}$

Dessa forma, a dignidade da pessoa humana é finalmente elevada à condição suprema, um verdadeiro ponto de partida para a construção dos ordenamentos jurídicos a partir de então. Entretanto, as raízes filosóficas da dignidade, que finalmente foram incorporadas ao sistema jurídico podem ser encontradas em momento histórico pretérito, o fim do século XVII e início do século XVIII, na obra de Emmanuel Kant. Leciona Ricardo Lobo Torres: "A criação de uma Teoria dos Direitos Fundamentais coincide com o desenvolvimento da Teoria da Justiça e se faz a partir da 'virada kantiana' isto é, do retorno ao pensamento filosófico-jurídico às raízes lançadas por Kant." 34

De fato, a justificativa dos Direitos Humanos está na Dignidade da Pessoa Humana. É o que se extrai do próprio preâmbulo da Declaração da $\mathrm{ONU}^{35}$ e da atual

33 Emblemática são as palavras de Gustav Radbruch, na carta circular aos alunos da faculdade de Direito da Universidade de Heildeberg, quando do retorno às atividades após a guerra: "Esta concepção da lei e sua validade, que chamamos positivismo, foi a que deixou sem defesa o povo e os juristas contra as leis mais arbitrárias, mais cruéis e mais criminosas. Torna equivalentes, em última análise, o direito e a força, levando a crer que só onde estiver a segunda estará o primeiro. RADBRUCH, Gustav. Cinco minutos de filosofia do direito." in MONCADA, Luís Cabral. Filosofia do direito. 5. ed. Coimbra: Coimbra editores, 1974. p. 417. A obra de Radbruch, aliás, é símbolo desta mudança de paradigma jurídico-científico. Isto porque, ao se confrontar o próprio conceito de Direito antes e depois da Segunda Guerra Mundial, nota-se clara transformação no que concerne à necessária incorporação da busca da efetivação da Justiça pelo Direito. É o que constata Henrich Scholler: [...], em 1932, Radbruch marcou o direito como um conceito cultural. Segundo este, o Direito é uma realidade, que tem o sentid de servir ao caminho do Direito ou à idéia de Justiça. Em outro lugar, após a Segunda Guerra Mundial: "Direito é o que tem a finalidade e realizar a justiça”. SCHOLLER, Henrich; RADBRUCH, Gustav. In: BARRETTO, Vicente de Paulo. Dicionário de flosofia do direito. São Leopoldo: Unisinos, 2006. p. 685.

34 TORRES, Ricardo Lobo. O direito ao minimo existencial. Rio de Janeiro: Renovar, 2009. p. 25-26. Explicanos, ainda, que a expressão "kantische Wende" se deve a Otfried Höffe, indicando a reaproximação entre ética e direito, com a fundamentação moral dos direitos humanos e a busca da efetivação da justiça fundada no imperativo categórico. HÖFFE, Otfried. Kategorische Rechtsprinzipien. Ein Kontrapunkt der Moderne. Frankfurt: Suhrkamp, 1990. p. 351 apud Idem. nota 58.

35 "Considerando que o reconhecimento da dignidade inerente a todos os membros da familia humana e de seus direitos iguais e inalienáveis é o fundamento da liberdade, da justiça e da paz no mundo, [...] a Assembléia Geral proclama a presente Declaração Universal dos Direitos Humanos [...]. ORGANIZAÇÃO 
Magna Carta Nacional, que a tem como um princípio fundamental (art. $1^{\circ}$ III, CRFB). Dentre as inúmeras asseverações que preenchem de conteúdo o princípio da dignidade da pessoa humana, lança-se de mão daquela elaborada por Maria Celina Bodin de Moraes, para quem o princípio da Dignidade se expressa mediante quatro corolários: liberdade, igualdade, solidariedade e integridade psicofísica. ${ }^{36}$

Entretanto, "o problema fundamental em relação aos direitos do homem, hoje, não é tanto o de justificá-los, mas o de protegê-los. Trata-se de um problema não filosófico, mas político" 37 Dessa maneira, os Estados Soberanos passam a elencar um extenso Rol de direitos fundamentais, tal como de direitos sociais, difusos e coletivos e etc.

Essa foi a opção de nossa atual Carta Magna, cuja natureza analítica a ela inerente fez com se inserisse já no art. $5^{\circ}$ a enumeração dos direitos e garantias fundamentais, sem excluir aqueles decorrentes do regime e dos princípios por ela adotados, ou dos tratados internacionais em que o Brasil figure como parte $\left(\S 2^{\circ}\right)$, sendo que, quando aprovados por quórum especial e contidos em tratados sobre Direitos Humanos poderão ter status de emenda constitucional $\left(\S 4^{\circ}\right) .^{38}$

Quanto à abrangência dos direitos humanos, sabe-se que duas visões contrapõem-se diametralmente. A primeira delas identifica neles os direitos sociais e econômicos além dos de primeira geração, de grande respaldo entre a Doutrina do Direito Internacional. A segunda, por sua vez, restringe o conteúdo dos direitos humanos aos direitos da liberdade, direitos individuais, direitos civis ou direitos fundamentais. A latere das distinções, o que nota é que os direitos humanos, hoje, encontram-se em sua maioria

DAS NAÇÕES UNIDAS. Declaração Universal dos Direitos Humanos. Preâmbulo.

36 MORAES, Maria Celina Bodin de. Danos à pessoa humana. Uma leitura civil-constitucional dos danos morais. Rio de Janeiro: Ed. Renovar, 2003. p. 85.

37 BOBBIO, Norberto. A era... cit., p. 24.

38 Esta foi a redação dada ao dispositivo pela E.C. 45/04. Insta ressaltar, porém, que, em se tratando de Tratados sobre Direitos Humanos aprovados anteriormente à manifestação do poder constituinte derivado reformador, vem prevalecendo no Supremo Tribunal Federal a tese da supralegalidade, embora sujeição à Constituição. Foi o ocorrido no caso da prisão do depositário infiel: "Desde a adesão do Brasil, sem qualquer reserva, ao Pacto Internacional dos Direitos Civis e Políticos (art. 11) e à Convenção Americana sobre Direitos Humanos - Pacto de San José da Costa Rica (art. $7^{\circ}, 7$ ), ambos no ano de 1992, não há mais base legal para prisão civil do depositário infiel, pois o caráter especial desses diplomas internacionais sobre direitos humanos lhes reserva lugar específico no ordenamento jurídico, estando abaixo da Constituição, porém acima da legislação interna. O status normativo supralegal dos tratados internacionais de direitos humanos subscritos pelo Brasil, dessa forma, torna inaplicável a legislação infraconstitucional com ele conflitante, seja ela anterior ou posterior ao ato de adesão. Assim ocorreu com o art. 1.287 do Código Civil de 1916 e com o Decreto-Lei n. 911/69, assim como em relação ao art. 652 do Novo Código Civil (Lei n. 10.406/2002)". (STF RE 466.343, Rel. Min. Cezar Peluso, voto do Min. Gilmar Mendes, julgamento em 3-12-08, DJE de 5-6-09). No mesmo sentido: RE 349.703, Rel. p/ o ac. Min. Gilmar Mendes, julgamento em 3-12-08, Plenário, DJE de 5-6-09. BRASIL. SUPREMO TRIBUNAL FEDERAL. A Constituição e o Supremo. Disponivel em: <http://www.stf.jus.br/portal/ constituicao/constituicao.asp >. Acesso em 14 mar. 2010. 
positivados pelos ordenamentos jurídicos nacionais, em perfeita consonância formal com as Declarações em sede internacional.

Assim, se é mais importante efetivá-los do que os positivar, imperioso que, hoje, época em que o paradigma jurídico-científico é o da aceitação do caráter normativo dos valores, elevados à condição de princípios do ordenamento, encontremos a matriz comum entre a dignidade humana e democracia, qual seja não só a liberdade de expressão e comunicação, como a própria liberdade como fonte de legitimação dos direitos subjetivos constitucionais dela decorrentes. Conclui-se com Ricardo Lobo Torres:

Os direitos humanos se aproximam do conceito de direitos fundamentais, pois se referem a os direitos decorrentes da própria natureza dos homens. [...] Mas nada desaconselha que a expressão seja tomada como sinônimo de direitos fundamentais e direitos da liberdade, que lhes servem de fonte de legitimação, inclusive quanto ao aspecto de necessidade de proteção positiva mínima pelo Estado [...] os direitos humanos - human rights - incluem liberdades "de" (freedom from), como por exemplo, detenção e tortura; liberdades "para" (freedom to), como expressão e reunião; e direitos à satisfação de necessidades humanas básicas, como alimentação (food) e moradia (housing). ${ }^{39}$

\section{Jusfundamentalidade dos direitos da liberdade}

Conforme já aviltado, a inserção de elementos axiológicos, criando-se uma tábua de valores no ordenamento jurídico, alterou profundamente as bases da ciência jurídica moderna, evidenciando a urgência de uma revisão metodológica no proceder da argumentação jurídica. Relevantes, nesse momento, as conquistas científicas de Robert Alexy.

Da obra do autor, destacam-se algumas passagens. A primeira delas é a ereção de uma dogmática própria da argumentação jurídica como um caso especial do discurso racional prático. Ou seja, na trilha delineada por Kant, afirma que as pretensões racionais das normas morais são de validade universal, somente podendo ser aceitos como verdadeiros quando confrontados racionalmente, motivados por uma questão prática relevante. Dessa forma, há necessidade de fundamentação racional das decisões para que se possa julgar, no caso prático relevante, determinado conflito. In verbis:

39 TORRES, Ricardo Lobo. Direitos fundamentais. In: BARRETTO, Vicente de Paulo. Dicionário de filosofia do direito. São Leopoldo: Unisinos, 2006. p. 243 (Texto adaptado). Nessa auréola, buscando ressaltar a matriz comum às diferentes terminologias que refletem as escolas jusfilosóficas a que se vinculam, encerra asseverando que "os direitos fundamentais (ou humanos, ou civis, naturais, da liberdade, individuais) são os direitos preexistentes ao ordenamento jurídico, inalienáveis imprescritíveis e dotados de eficácia erga omnes" (p. 245), abrangendo uma dimensão mínima de direitos sociais. 
Esta dificuldade de conseguir uma categorização clara de procedimentos diante dos juízes deve na verdade excluir a possibilidade de designá-los meramente como discurso, mas por outro lado, significa que eles não podem ser teoricamente entendidos como referência ao conceito de discurso. Este último ponto conecta-se particularmente com o fato de que $\left(\operatorname{sic}^{*}\right)$ os participantes exigirem argumentar a racionalidade. Assim, nos processos civis, via de regra as partes não desejam convencer uma à outra [...], no entanto, exigem falar de um modo que toda pessoa racional teria de concordar com seu ponto de vista. Eles ao menos pretendem estar apresentando argumentos tais que obteriam concordância em condições ideais. A teoria do discurso, portanto, não só é adequada ao entendimento teórico da argumentação envolvida, é necessária para entendê-la. ${ }^{40}$

Posteriormente, desenvolve sua famigerada Teoria dos Direitos Fundamentais, de menção indispensável para concretização da jurisdição constitucional na maioria das Cortes Constitucionais ao redor do globo. Parte da distinção estabelecida por Ronald Dworkin entre regras e princípios, todos espécies de normas, ${ }^{41}$ para enfrentar a problemática da colisão de valores, sujeitando-os à ponderação. In Verbis:

Com frequência, não são regra e princípio, mas norma e principio ou norma e máxima que são contrapostos. Aqui, regras e princípios serão reunidos sob o conceito de norma. Tanto regras quanto princípios são normas, porque ambos dizem o que deve ser. Ambos podem ser formulados por meio de expressões deônticas básicas do dever, da permissão da proibição. Princípios são, tanto quanto regras, razoes para juízos concretos do dever-ser, ainda que de espécie muito diferente. A distinção entre regras e princípios é, portanto, uma distinção entre duas espécies de normas. ${ }^{42}$

Em termos genéricos, a técnica da ponderação trata do sopesamento entre valores expressos por direitos fundamentais e elevados à condição de princípios. Trata o

40 ALEXY, Robert. Teoria da argumentação jurídica. 2. ed. Tradução Zilda Hutchinson Schild Silva. São Paulo: Landy, 2001. p. 217.

41 "My immediate purpose, however, is to distinguish principles in the generic sense form rules [...]. The difference between legal principles and rules is a logical distinction. Both sets standard poit to particular decisions about legal obligation in particular circumstances, but they differ in the character of the direction they give. Rules are applicable in an al-or-nothing fashion. If the facts a rule stipulates are given, then either the rule is valid, in which case the answer it supplies must be accepted, or it is not, in which case it contributes nothing to the decision". DWORKIN, Ronald. Is law a system of rules? In: philosophy of law. Oxford: Oxford University Press, 1984, p. 45. (Org.). The

42 ALEXY, Robert. Teoria dos direitos fundamentais. Tradução de Virgílio Afonso da Silva. São Paulo: Malheiros, 2008. p. 87. 
autor, pioneiramente, de uma lei de colisão ${ }^{43}$ que permite que seja retirada da situação em concreto uma resposta válida apta a justificar a prevalência de um direito sobre outro. ${ }^{44} \mathrm{O}$ princípio da ponderação ${ }^{45}$ extrai dos princípios morais positivados constitucionalmente, ou seja, normas, mandados de otimização através de três processos: adequação, necessidade e proporcionalidade strictu sensu. Conclui Eduardo Ribeiro Moreira: "Essas três fases adequação, necessidade e proporcionalidade estrita - ajudam a pautar a racionalidade na opção por um dos princípios escolhidos e diminuem a incerteza que paira sobre a solução de um caso difícil" 46

A evolução da própria obra de Alexy, se fez pelo rebater de suas críticas, o que apenas denota sua repercussão na ciência jurídica atual. Costuma-se afirmar que a principal delas é a de que atenua o radicalismo do princípio da ponderação, perdendo força a idéia de que os princípios estão sempre em pé de igualdade hierárquica até que o caso concreto venha a apresentar uma situação de colisão. Aceita, assim, a possibilidade de prioridades prima facie de princípios, embora não absolutas por si só. ${ }^{47}$

Entra aqui a importância dos chamados direitos da liberdade. Prescindindose das noções que os igualam por inteiro aos direitos fundamentais, o que se percebe é que há direitos mais diretamente vinculados à liberdade, cujo exercício pelos cidadãos muitas vezes denota ações não só omissivas do Estado, como prestações positivas a garantir seu exercício. Como a democracia está intimamente ligada ao exercício da liberdade,

43 Sintetizando a fórmula adotada pelo Tribunal constitucional alemão: "Quanto maior for o grau de nãosatisfação ou de afetação de um princípio, tanto maior terá que ser a importância da satisfação do outro." ALEXY, Robert. Teoria dos... cit., p. 167.

$44[\ldots]$ o sopesamento não é um procedimento por meio do qual um interesse é realizado às custas de outro "de forma precipitada". De acordo com esse modelo, o sopesamento é tudo, menos um procedimento abstrato generalizante. Seu resultado é um enunciado de preferências condicionadas, ao qual de acordo com a lei de colisão, corresponde uma regra de decisão diferenciada. Do próprio conceito de princípio decorre a constatação de que os sopesamentos não são uma questão de tudo ou nada, mas uma tarefa de otimização. [...] Também não é procedente a objeção segundo a qual não haveria um parâmetro com base no qual o sopesamento pudesse ser decidido e que, por isso, a máxima do sopesamento de interesses seria uma "fórmula vazia". Ainda que o sopesamento em si não estabeleça um parâmetro com o auxílio do qual os casos possam ser decididos de forma definitiva, o modelo de sopesamento como um todo oferece um critério, ao associar a lei da colisão à teoria da argumentação jurídica racional. ALEXY, Robert. Teoria dos... cit., p. 173-174.

45 Conceitua Luis Roberto Barroso: "A ponderação consiste, portanto, em uma técnica de decisão jurídica aplicável a casos dificeis, em relação aos quais a subsunção se mostrou insuficiente, sobretudo quando uma situação concreta dá ensejo à aplicação de normas de mesma hierarquia que indicam soluções diferenciadas." BARROSO, Luís Roberto. Liberdade de expressão versus direitos da personalidade. Colisão entre direitos fundamentais e critérios de ponderação. In: SARLET, Ingo Wolfgang (Org.). Direitos fundamentais, informática e comunicação: algumas aproximações. Porto Alegre: Livraria do advogado, 2007. p. 72.

46 MOREIRA, Eduardo Ribeiro. Neoconstitucionalismo: a invasão da constituição. São Paulo: Método, 2008. p. 102 .

47 Cf. Albuquerque, Paulo Antonio de Menezes. Alexy, Robert (verbete). In: BARRETTO, Vicente de Paulo. Dicionário de filosofia do direito. São Leopoldo: Unisinos, 2006. p. 35. 
principalmente no que concerne aos direitos políticos, há de se afirmar que não só o próprio princípio democrático é um direito da liberdade como os direitos políticos também o são.

Nesse sentido, Ricardo Lobo Torres ensina que são características básicas dos direitos da liberdade: serem pré-constitucionais, inerentes à pessoa humana; deterem validade erga omnes; não se esgotarem no rol do art. $5^{\circ}$ da Carta Magna nem em catálogo preexistente; aparecerem sob formas indeterminadas, por serem dotados de historicidade, ínsita ao seu conteúdo cultural; serem indefiníveis por tocarem a todos os homens independente de sua nacionalidade; abrangerem o status negativus e o status positivus libertatis, protegendo o cidadão contra a constrição do Estado ou de terceiros além de gerarem a obrigação de entrega de prestações positivas estatais individuais para a garantia da liberdade e das condições essenciais; postularem garantias institucionais e processuais que provocam custos gerais para o Estado e; serem plenamente justificáveis, independente de complementação legislativa, gozando de eficácia imediata. ${ }^{48}$

Logo, partindo-se da premissa que a liberdade de expressão e comunicação é um direito fundamental de primeira geração, decorre da dignidade da pessoa humana no que toca à liberdade e constitui um princípio de primazia prima facie, verte-se à importância da democracia como ambiente necessário ao seu pleno exercício, a ser garantido pelo Estado seja omissivamente seja de modo por meio de facere determinado.

\section{O papel da democracia na consolidação dos direitos da liberdade}

Por todo o exposto, percebe-se a intrínseca relação entre dignidade humana e democracia, mormente da necessária dependência dos direitos da liberdade de um âmbito democrático para seu real florescimento. Paulo Bonavides ensina-nos que para a consecução do Estado Social seriam princípios aplicáveis à teoria constitucional da democracia participativa: Princípio da dignidade da pessoa humana (art. $1^{\circ}$, III), soberania popular (art. $1^{\circ}$ parágrafo único), soberania nacional (art. $1^{\circ}$ I) e unidade da Constituição. Atendo-se ao primeiro, conclui que é o que dá alma à própria Constituição e à sociedade democrática e pluralista que deve caracterizar um Estado comprometido com a defesa dos Direitos Humanos sendo o "valor dos valores numa sociedade democrática e participativa" 49

Em outras palavras, num estado que cultua a liberdade como premissa básica, a "nova democracia" que reaproxima os cidadãos dos assuntos afeitos a polis de forma supera o individualismo egocêntrico do homo faber pelo enaltecimento da pluralidade, instrumentada por formas de concretização do próprio regime democrático, ilustrando

48 Cf. TORRES, Ricardo Lobo. O direito ao mínimo... cit., p. 40.

49 Id. Ibid., p. 10. 
a vitória do animal laborans..$^{50}$ Este parece ser o sentido da democracia atual, que tem no chamado terceiro setor formas de reinserção dos indivíduos na discussão política, a importância da solidariedade enquanto corolário da dignidade, a dirigir e redimensionar a liberdade de expressão e comunicação na sociedade de massa.

Frank I. Michelman aponta a diferença entre liberdade de expressão tênue e densa, sendo a primeira uma conduta meramente omissiva do Estado, ao passo que a segunda demande limitações que garantam a possibilidade de seu exercício por todos equanimente. Esta se iguala à democrática, pois concretiza relações de proporcionalidade entre a expressão da subjetividade dos indivíduos sem perder de vista os interesses da sociedade. ${ }^{51}$

Conclui Paulo Ferreira da Cunha que "na Liberdade, pelo menos a liberdade civil e política, começa, em grande medida com a liberdade de expressão e comunicação." Uma vez assegurados direitos básicos como vida a integridade e a não constrição física da liberdade, a refletir as três expressões da dignidade (liberdade, igualdade, integridade psicofísica) somente a "dignidade comunicativa" que concebe os homens enquanto semelhantes em um ambiente comum, "em sua expressão social" é que perfará sua real proteção. ${ }^{52}$ Esta parece ser a ponte entre democracia e dignidade da pessoa humana na atualidade por meio da liberdade de expressão e comunicação: a garantia dos direitos da liberdade via solidariedade estatal.

5. O caso da democracia representativa: insuficiência dos mecanismos constitucionais de consecução da democracia participativa no Brasil

Ninguém pretende que a democracia seja perfeita ou sem defeito. Tem-se dito que a democracia é a pior forma de governo, salvo todas as demais formas que têm sido experimentadas de tempos em tempos.

Winston Churchil

A célebre frase atribuída ao primeiro ministro britânico, que comandou o país durante a segunda guerra mundial, demonstra a característica principal do regime democrático: a possibilidade de rever os próprios equívocos e mudar quando necessário.

so Termos utilizados por Hanna Arendt. Cf. ARENDT, Hanna. A condição humana. 10. ed. Rio de Janeiro: Forense Universitária, 2008. p. 333-338.

51 Cf. MICHELMAN, Frank I. Relações entre democracia e liberdade de expressão: discussão de alguns argumentos. Trad. Marcelo Fensterseifer e Tiago Fensterseifer. Rev. Ingo Wolfgang Sarlet. In: SARLET, Ingo Wolfgang (Org.). Direitos fundamentais, informática e comunicação: algumas aproximações. Porto Alegre: livraria do advogado, 2007. p. 59.

52 CUNHA, Paulo Ferreira da. Direito à informação ou deveres de proteç̧ão informativa do Estado? In: Id. p. 164. 
Em outras palavras, um meio de expressão política que desde a antiguidade vem sendo praticada e renova a si mesma de acordo com o momento histórico em que é analisada.

Sabe-se que, na teoria dos sistemas, quando determinado sistema social defronta-se com seus limites deve readaptar-se para que consiga se organizar novamente, preservando sua essência. A evolução, assim, não é medida pelo processo linear crescente, mas sim pelo nível de complexidade que consegue atingir. Quando os limites de seu entorno chocam-se com outros subssistemas sociais, é necessário que esteja aberto a conhecer para que novas formas de seu exercício sejam concebidas para sua preservação. Segundo Niklas Luhmann, essa característica se denomina clausura operativa. Sendo a autopoiesis (do latim auto - a si mesmo - e poiesis - produzir), algo necessário a ser atingido em todos os sistemas, o sistema social utiliza-se de meios para reduzir sua complexidade interna aumentando a complexidade externa. Explica:

Debido a la clausura operativa, se constituye una unidad de un ámbito; luego ese ámbito se convertirá en el entorno dentro de esa unidad. No se niega ni la existencia ni la referencia Del entorno. [...]. Únicamente afirmamos que el sistema produce las relaciones con dicho entorno a partir de sus propias operaciones; estas operaciones son posibles gracias a la integración de un urdimbre recursiva que designamos como clausura Mas brevemente: la apertura es viable solo sobre la base de su cierre. ${ }^{53}$

Em outras palavras, como um ser vivo que cresce e, para tal, necessita de elementos externos, o Direito vê em seu entorno uma crescente complexidade externa à que deve reagir. Neste viés claramente se inserem os meios de comunicação de massa ou as novas tecnologias, a criarem novos "ramos" da própria ciência do Direito.

Quando tantos países adotam o regime democrático e não conseguem exercê-lo devidamente, ou quando, especificamente no caso brasileiro, os instrumentos de exercício dos direitos políticos na democracia representativa e semidireta mostram-se claramente insuficientes para as atuais demandas sociais, algo deve ser feito.

Explica-nos Marcelo Neves que os sistemas jurídicos dos países da modernidade periférica, como o Brasil, vivem um impasse. Isto porque a chamada autopoiese, ou seja, a capacidade de se autocompletar através da funcionalização de elementos externos, fica extremamente prejudicada. Em minúcias, o sistema jurídico democrático se encontra jungido a outros interesses, mormente econômicos e políticos das classes dominantes, ocasionando seu não funcionamento. ${ }^{54}$

s3 LUHMANN, Niklas. El derecho de la sociedad. Trad. Javier Torres Nafarrate. México: Universidad Iberoamericana, 2002. p. 132. Grifo nosso.

54 É o que chama de alopoiesis, advnida da junção dos vocábulos de origem grega alo (outro, diferente) e poiesis (produção, criação), que designa a reprodução de um sistema por mecanismos não pertencentes a si 
Isso se exemplifica pelo atual descaso dos cidadãos para com a política, tal como seu próprio distanciamento dos partidos políticos, principais atores do jogo democrático representativo, que cada vez mais têm menos adeptos, fato também conhecido por crise de representatividade. Na esteira de Joaquim Falcão, infere-se conclusivamente que é preciso "inventar" ${ }^{55}$ É preciso que busquemos soluções para a própria sobrevivência do regime democrático, não só constitucionalmente positivado, mas contido em todas as Cartas de Direitos humanos em sede Internacional. E para que o discurso não caia no vazio completo, seguem algumas proposições específicas.

6. A cidadania do século XXI e o papel do terceiro setor: superando a dicotomia liberal Estado vs. Sociedade Civil

Posta a importância da democracia na concretização jurídica da liberdade e, simultaneamente, as dificuldades por que passa o regime democrático atual, esgotado pelos limites que o prendem às raízes liberais idealizadas pelas revoluções burguesas, chega-se às linhas finais deste excerto visando apontar algumas possíveis formas de superação desse impasse.

Muitos procuraram conceituar, ou expressar em palavras o que seria a democracia. Entretanto, como se pôde notar, o regime democrático que desde os gregos fora praticado, hoje é positivado nos ordenamentos jurídicos nacionais, elevado a princípio fundamental na maioria das constituições dos Estados Nacionais. Ademais, a democracia passa a figurar nos discursos em sede internacional, como princípio político deontológico a todos os Estados, principalmente ligados à intrínseca relação entre a dignidade dos indivíduos, dos Homens ali envolvidos.

Em posição diametralmente oposta, desafortunadamente, parecem estar os fatos. Afinal, o que se nota é que, principalmente nos países da modernidade periférica, como o Brasil, o sistema político se demonstra dominado por interesses outros que nem sempre se interessam pela manutenção da dinâmica do jogo democrático. As tão veneradas regras do jogo parecem manter um jogo que para muitos já não vale mais ser jogado. $O$ fato de estarem constitucionalizadas escondem por detrás de uma formal liberdade as injustiças que maculam materialmente os princípios constitucionais. ${ }^{56}$

mesmo. In vebis: En la medida en que, al contrario, los agentes del sistema jurídico estatal ponen de lado el código-diferencia "lícito/ilícito" y los respectivos programas y criterios, conduciéndose u orientándose principal y frecuentemente basándose en prescripciones directas de la economía, del poder, de las relaciones familiares etc., cabe, sin duda, sostener la existencia de la alopoiesis del Derecho. Cf. NEVES, Marcelo. De la autopoiesis a la alopoiesis del Derecho. Doxa Cuardenos de Filosofia del Derecho, Alicante, v. 19, p. 403-420, 1996. p. 416.

55 Cf. FALCÃO, Joaquim. op. cit., p. 67

56 Com propriedade, sintetiza Norberto Bobbio: "[...] o que distingue um sistema democrático dos sistemas não democráticos é um conjunto de regras do jogo. Mais precisamente, o que distingue um sistema democrático 
Afirma-se que se distinguem formalmente, três visões históricas da democracia: direta, indireta e semidireta ou, simplesmente, não representativa ${ }^{57} \mathrm{~A}$ indireta fora consagrada entre os modernos e parcialmente adotada entre nós, vez que o sistema brasileiro se baseia no sistema pluripartidário (art. 17, caput, CRFB), prevendo pontuais formas de exercício da democracia semidireta (art. 14, CRFB). Partido político é um conceito mais sociológico do que jurídico. Entretanto, pode-se afirmar que é uma "forma de agremiação de um grupo social que pode se organizar, coordenar e instrumentar a vontade popular com o fim de assumir para si um programa de governo" ${ }^{58}$ Muitas são as classificações que procuram buscar uma causa à segmentação dos partidos políticos. Dos reais e pessoais de David Hume, aos ideológicos e patronais Max Weber, chegando-se aos de opinião e de massa, preconizados por Georges Burdeau, ${ }^{59}$ fato é que a realidade partidária, principalmente no Brasil.

A complexidade dos interesses hoje expresso em nossa sociedade multicultural ilustra a insuficiência da sistemática proposta. Os mecanismos de controle constitucionalmente concebidos ${ }^{60}$ já não mais são suficientes para conter a falta de fidelidade partidária, ${ }^{61}$ de transparência financeira, de honestidade ideológica. O emblemático caso dos "troca troca" de partidos nas eleições para a última legislatura apenas ilustra quão urgente é a necessidade de uma reforma política no Brasil. ${ }^{62}$

não é apenas o fato de possuir as suas regras do jogo (todo sistema as tem, mais ou menos claras, mais ou menos complexas), mas sobretudo o fato de que estas regras, amadurecidas ao longo de séculos de provas e contraprovas, são muito mais elaboradas que as regras de outros sistemas e encontram-se hoje, quase por toda parte, constitucionalizadas [...]. Mas será possível, num sistema como o sistema democrático, que é tão compacto e coerente do ponto de vista dos procedimentos por ele criados e que estão verificados pela experiência e cristalizados há séculos, distinguir com tanta segurança as regras a serem mantidas e as que devem ser descartadas? Conservaremos o sufrágio universal mas não a liberdade de opinião? a liberdade de opinião mas não a pluralidade dos partidos? a pluralidade dos partidos mas não a proteção jurídica dos direitos civis? Em suma, afirmar que nem todas as regras do jogo serão suprimidas é um modo de subtrair-se à obrigação de precisar o próprio ponto de vista a respeito de um problema tão central como é exatamente este das regras do jogo, e é sobretudo um indício da absoluta ausência de idéias acerca da sua possível resolução." BOBBIO, Norberto. O futuro da democracia: uma defesa das regras do jogo. Tradução de Marco Aurélio Nogueira. Rio de Janeiro: Paz e Terra, 1986. p. 66-67.

57 Cf. BONAVIDES, Paulo. Ciência politica. 10. ed. São Paulo: Malheiros, 2000. p. 346.

58 SILVA, José Afonso da. Comentário Contextual à Constituição. 6. ed. São Paulo: Malheiros: 2009. p. 235.

59 Cf. BONAVIDES, Paulo. Ciência... op. cit., p. 464-467.

${ }^{60}$ Segundo José Afonso da Silva, três seriam essas modalidades: qualitativo, quantitativo e financeiro. Cf. SILVA, José Afonso da. Comentário... op. cit., p. 237. A legislação aplicável aos partidos políticos, disciplinando, incluso acerca do financiamento e do controle desses recursos é a Lei n. 9096/95, arts. 30 a 44.

${ }_{61}$ Insta ressaltar a interpretação evolutiva preconizada pelo TSE e pelo STF no que concerne à mudança de entendimento já declarada pelo STF quando do julgamento do MS 20.297. Em suma, conclui-se que em se tratando de fidelidade partidária: "o mandato 'pertenceria' ao Partido. [...] O Supremo Tribunal Federal, por ocasião do julgamento dos Mandados de Segurança 26.602, 26.603 e 26.604 reconheceu a existência do dever constitucional de observância do princípio da fidelidade partidária. [...] São constitucionais as Resoluções 22.610/2007 e 22.733/2008 do Tribunal Superior Eleitoral". (ADI 3.999 e ADI 4.086, Rel. Min. Joaquim Barbosa, julgamento em 12-11-08, Plenário, DJE de 17-4-09)

62 Este é o entendimento do ministro Gilmar Ferreira Mendes. Cf. MENDES, Gilmar Ferreira; COEHO, 
Por essas e por outras, é necessário que as próprias relações de poder e de ascensão a ele sem deixar de lado as regras do jogo devam ser revistas. Eis aí a importância do chamado terceiro setor. Joaquim Falcão dá as coordenadas iniciais da problemática a ser enfrentada. Preconiza que quem detém a força política de fato não são os partidos, mas as organizações sociais. Embora os partidos políticos detenham o monopólio legal de apresentar candidatos às eleições, isto não é suficiente, pois carecem de monopólio político. ${ }^{63}$

Com efeito, o fortalecimento de uma sociedade civil no Brasil. O também chamado terceiro setor, em verdade, constitui um conjunto de entes privados cujos interesses institucionais transcendem seus limites, sendo considerados de caráter público. Ou seja, instituições que não fazem parte da administração direta nem indireta, mas desempenham funções de suma importância para a sociedade. Isto porque, na atmosfera democrático participativa, constitui importante arma na defesa de interesses muitas vezes não passíveis de serem politicamente alçados no rígido sistema partidário.

Os exemplos são muitos e não param de surgir: OSCIPs, ${ }^{64} \mathrm{OSSs},{ }^{65}$ Pessoas de cooperação governamental ou Serviços Sociais Autônomos, ${ }^{66}$ fundações publicas e privadas, e tantas outras formas de associação não previstos legalmente, que tampouco devem se jungir à ilegalidade.

Logo, quando nos debruçamos sobre a forma de democracia adotada pelo Brasil, perquirindo-se qual a modalidade constitucionalmente adotada - direta, representativa ou participativa, responde-se: as três. Afinal os modelos de democracia não são seqüenciais e excedentes, são complementares e concomitantes. ${ }^{67}$

Nessa mesma linha, Paulo Bonavides avança ainda mais. Partindo-se da premissa de que a democracia participativa é um direito fundamental de quarta geração, conclui:

A democracia positivada da quarta geração há de ser necessariamente, uma democracia direta. Materialmente possível graças aos avanços da tecnologia de comunicação, e legitimamente sustentável graças à informação correta e às aberturas

Inocêncio Mártires; BRANCO, Paulo Gustavo Gonet. Curso... cit., p. 826. Para o quadro completo dos deputados que perderam os cargos $V$. Idem. p. 823-824.

63 Cf. FALCÃO, Joaquim. op. cit., p. 40.

64 Lei n. 9790/99 regulamentada pelo decreto n. 3.100/99.

65 Lei 1 . $9637 / 98$.

66 É o caso do já conhecido sistema "S", constituído por SESC, SENAI, SESI, SEBRAE, SENAR, SENAT, SEST e tantos outros de regime jurídico híbrido, tendo personalidade jurídica de direito privado, mas sujeitando-se às regras sobre licitações e contratos (8666/93) e sofrendo controle externo pelo TCU e TCEs, demonstrando a inserção e outros elementos na Teoria Geral do Estado, que mesclam o "público" e o "privado" como preteritamente concebido à época da construção do Estado Moderno. Cf. SANTOS FILHO, José dos Santos Carvalho. Manual de direito administrativo. 22. ed. Rio de Janeiro: Lúmen Juris, 2009. p. 509-518.

67 Cf. FALCÃO, Joaquim. op. cit., p. 87. 
pluralistas do sistema. Desse modo, há de ser também uma democracia isenta já das contaminações da mídia manipuladora, já do hermetismo de exclusão, de índole autocrática e unitarista, familiar aos monopólios do poder. Tudo isso, obviamente, se a informação e o pluralismo vingarem por igual como direitos paralelos e coadjutores da democracia; esta, porém, enquanto direito do gênero humano, projetado e concretizado no último grau de sua evolução conceitual..$^{68}$

E, tornando realidade esses postulados, chega-se finalmente ao caso gerador do estudo ora esboçado, o Marco Regulatório Civil da Internet Brasileira ou simplesmente Marco Civil, uma forma colaborativa de construção de um projeto de lei, de iniciativa conjunta da Secretaria de Assuntos Legislativos do Ministério da Justiça (SAL/MJ), em parceria com a Escola de Direito do Rio de Janeiro da Fundação Getulio Vargas (DIREITO RIO). ${ }^{69}$

A iniciativa dá vida aos postulados até aqui preconizados. Afinal, utilizando de uma potente ferramenta à manifestação da liberdade de expressão e comunicação e de sua clara vocação como meio plural e democrático de transmissão do conhecimento, o processo ocorre em duas fases. ${ }^{70}$

A primeira delas fora a de discussões em um canal em linguagem blog para a expressão dos diversos pontos de vista acerca de tópicos predeterminados: direitos individuais e coletivos (privacidade, liberdade de expressão e direito de acesso à net); responsabilidade civil de provedores e usuários na Internet; e as políticas públicas acerca da Internet. Ao final da primeira etapa, apresentou-se a proposta de anteprojeto de lei, sintetizando os debates realizados.

A segunda fase ocorreu da mesma forma, desta vez tendo como base já a minuta do anteprojeto de lei apresentado na fase anterior. Cada momento teve duração de 45 dias, onde puderam ser expressas as opiniões de todos os interessados, com seus diversos pontos de vista.

E os milhares de posts no blog, somente demonstram a força de tal meio de comunicação, bem como o sucesso da iniciativa. Esta é apenas uma amostra do potencial da democracia participativa e do uso das novas ferramentas da comunicação na consecução da cidadania no século XXI.

\footnotetext{
68 BONAVIDES. Curso... cit., p. 571.

69 Ver <http://culturadigital.br/marcocivil/sobre/>. Acesso em: 18 mar. 2010.

70 Convém ressaltar que esta é uma premissa que tampouco se encontra imune a ponderações. Nesse sentido, Fábio Konder Comparato: "Sem dúvida, a invenção da internet, [...], veio alterar o esquema original de comunicação de massa, ao criar um ambiente de diálogo entre pessoas do mundo todo. Mas não extrapolemos inconsideravelmente os efeitos da democratização que esse avanço tecnológico irá produzir. Lembremo-nos de que o público usuário desses engenhos eletrônicos pertence à minoria do extrato econômico superior da sociedade. [...]" COMPARATO, Fábio Konder. Para que o povo tenha enfim a palavra! Revista de direito UFPR, Curitiba, n. 50. 2009. p.18.
} 
Enquanto a maioria dos projetos de lei que tramitam anos a fio em nossas casas legislativas iniciam a regulamentação da Rede por estabelecer sanções criminais, no mais das vezes transformando em condutas típicas práticas comuns dos usuários da Rede, o marco civil procura construir soluções chamando às discussões os que se interessam pelo estabelecimento de uma justa governança dos usuários da net.

Ou seja, começa-se pela força, pela punição, pela função coercitiva do direito. Explica-nos Michel Foucault que as relações de coerção no mais das vezes tem uma dúbia e cruel face oculta. Escondem por detrás dela relações de poder que perpassam diferentes instituições em diferentes épocas históricas. Logo, deve-se renunciar ao binômio violência-ideologia, propriedade-riqueza, Estado-Coerção, e a tantos outros dogmas. ${ }^{71}$

Logo, na sociedade atual, a dignidade humana é um princípio moral. Estabelece um dever-ser a todos aqueles que atuam na sociedade. Na Trilha traçada por Bobbio, a dignidade não se realiza sem liberdade, a qual necessariamente precisa de um ambiente democrático para seu ideal florescimento. Mas essa democracia não depende apenas de uma conduta omissiva do poder público, mas sim da criação de mecanismos para seu exercício.

Esse parece ser o espírito do Estado Social no século XXI, um Estado que não age para punir e se omite para dar liberdade, mas que no mais das vezes deve atuar positivamente para concretizá-la e garanti-la. Por cerre, a democracia na dita sociedade da informação é participativa, pois inclui antes de segregar e funde interesses públicos e privados, muitas vezes, por permitir os sujeitos do sistema democrático a jogarem um jogo que tem uma única regra: liberdade digna para todos.

São Paulo, março de 2010.

Referências

ALBUQUERQUE, Paulo Antonio de Menezes. Alexy, Robert. In: BARRETTO, Vicente de Paulo. Dicionário de filosofia do direito. São Leopoldo: Unisinos, 2006.

ALEXY, Robert. Teoria da argumentação jurídica. 2. ed. Tradução Zilda Hutchinson Schild Silva. São Paulo: Landy, 2001.

ALEXY, Robert. Teoria dos direitos fundamentais. Tradução de Virgílio Afonso da Silva. São Paulo: Malheiros, 2008.

ALVES, Eliana Calmon. Direitos de quarta Geração: biodiversidade e biopirataria. Revista do Tribunal Regional do Trabalho da $5^{a}$ Região, v.4, n.1, p.41-61, dez. 2002.

7 FOUCAULT, Michel. Vigiar e punir: nascimento da prisão. Tradução de Raquel Ramalhete. 20. ed. Petrópolis: Editora Vozes, 1999. p. 26. 
AMARAL, Roberto. Apontamentos para a reforma política: a democracia representativa está morta; viva a democracia participativa. Revista de Informação Legislativa, Brasília, n. 151. jul./set. 2001.

ARENDT, Hanna. A condição humana. 10. ed. Rio de Janeiro: Forense Universitária, 2008.

BARROS, Sérgio Resende de. In: Aulas proferidas no curso de graduação em Direito, na Faculdade de Direito da USP, compartilhadas com o Autor, nos anos de 2002-2003.

BARROSO, Luís Roberto. Liberdade de expressão versus direitos da personalidade. Colisão entre direitos fundamentais e critérios de ponderação. In: SARLET, Ingo Wolfgang (Org.). Direitos fundamentais, informática e comunicação: algumas aproximações. Porto Alegre: Livraria do advogado, 2007.

BOBBIO, Norberto. O futuro da democracia: uma defesa das regras do jogo. Tradução de Marco Aurélio Nogueira. Rio de Janeiro: Paz e Terra, 1986.

MORAES, Maria Celina Bodin de. Danos à pessoa humana. Uma leitura civil-constitucional dos danos morais. Rio de Janeiro: Ed. Renovar, 2003.

BONAVIDES, Paulo. Ciência política. 10. ed. São Paulo: Malheiros, 2000.

Bonavides, Paulo. Constituinte e iniciativa popular. Folha de São Paulo, São Paulo, 9 de Julho de 2007.

BRASIL. SUPREMO TRIBUNAL FEDERAL. A Constituição e o Supremo. Disponível em: <http:// www.stf.jus.br/portal/constituicao/constituicao.asp>. Acesso em: 14 mar. 2010.

CUNHA, Paulo Ferreira da. Direito à informação ou deveres de protecção informativa do Estado? In: SARLET, Ingo Wolfgang (Org.). Direitos fundamentais, informática e comunicação: algumas aproximações. Porto Alegre: livraria do advogado, 2007.

DWORKIN, Ronald. Is law a system of rules? In: DWORKIN, Ronald (Org.). The philosophy of law. Oxford: Oxford University Press, 1984.

FALCÃO, Joaquim. Democracia, direito e terceiro setor. 2. ed. Rio de Janeiro: FGV, 2006.

FARIAS, Edilsom Pereira de. Colisão de direitos: a honra, a intimidade, a vida privada e a imagem versus a liberdade de expressão e comunicação. 3. ed. rev. e atual. Porto Alegre: Sergio Antonio Fabris, 2008.

FERREIRA FILHO, Manoel Gonçalves. Curso de Direito Constitucional. 34. ed., atual. São Paulo: Saraiva, 2008.

FERREIRA FILHO, Manoel. Aspectos do direito constitucional contemporâneo. 2. ed. São Paulo: Saraiva, 2009.

FOUCAULT, Michel. Vigiar e punir: nascimento da prisão. Tradução de Raquel Ramalhete. 20. ed. Petrópolis: Editora Vozes, 1999.

GORE, Al. The Assault on Reason. USA: Penguin Press, 2007. 
GUTIÉRREZ. David Ortega. Derecho a la información versus derecho al honor. Madrid: Centro de estudos constitucionales, 1999.

HÄBERLE, Peter. A dignidade humana e a democracia pluralista - seu nexo interno. In: SARLET, Ingo Wolfgang (Org.). Direitos fundamentais, informática e comunicação: algumas aproximações. Porto Alegre: livraria do advogado, 2007.

HOBSBAWN, Eric J. A era das revoluções: 1789-1848. 5. ed. São Paulo: Paz e Terra, 1982.

LAVALLE, Adrián G., HOUTZAGER, Peter P., CASTELLO, Graziela. Democracia, Pluralização da Representação e Sociedade Civil. Lua Nova: revista de cultura e política. O futuro da representação. (n. 67, 2006). São Paulo: CEDEC, 2006.

LUHMANN, Niklas. A realidade dos meios de comunicação. Tradução Ciro Marcondes Filho. São Paulo: Editora Paulus, 2005.

LUHMANN, Niklas. El derecho de la sociedad. Trad. Javier Torres Nafarrate. México: Universidad Iberoamericana, 2002.

MENDES, Gilmar Ferreira; COEHO, Inocêncio Mártires; BRANCO, Paulo Gustavo Gonet. Curso de direito constitucional. São Paulo: Saraiva, 2009.

MICHELMAN, Frank I. Relações entre democracia e liberdade de expressão: discussão de alguns argumentos. Trad. Marcelo Fensterseifer e Tiago Fensterseifer. Rev. Ingo Wolfgang Sarlet. In: SARLET, Ingo Wolfgang (Org.). Direitos fundamentais, informática e comunicação: algumas aproximações. Porto Alegre: livraria do advogado, 2007.

MOREIRA, Eduardo Ribeiro. Neoconstitucionalismo: a invasão da constituição. São Paulo: Método, 2008.

NEVES, Marcelo. De la autopoiesis a la alopoiesis del Derecho. Doxa Cuardenos de Filosofia del Derecho, Alicante, v. 19, p. 403-420, 1996.

ORGANIZAÇÃ̃O DAS NAÇÕES UNIDAS. Declaração Universal dos Direitos Humanos.

RADBRUCH, Gustav. Cinco minutos de filosofia do direito. In: MONCADA, Luís Cabral. Filosofia do Direito. 5. ed. Coimbra: Coimbra Editores, 1974.

SANTOS FILHO, José dos Santos Carvalho. Manual de direito administrativo. 22. ed. Rio de Janeiro: Lúmen Juris, 2009. p. 509-518.

SCHOLLER, Henrich. RADBRUCH, Gustav. In: BARRETTO, Vicente de Paulo. Dicionário de filosofia do direito. São Leopoldo: Unisinos, 2006.

SILVA, José Afonso da. Comentário contextual à Constitução. 6. ed. São Paulo: Malheiros: 2009.

SILVA, José Afonso da. Comentário contextual à Constituição. 3. ed. São Paulo: Malheiros, 2007.

SILVA, José Afonso da. Poder constituinte e Poder Popular: estudos sobre a Constituição. São Paulo, Malheiros, 2000. 
SOUZA NETO, Cláudio Pereira de. Teoria constitucional e democracia deliberativa: um estudo sobre o papel do direito na garantia das condições para a cooperação na deliberação democrática. Rio de Janeiro: Renovar, 2006.

Souza Santos, Boaventura de. In: Joint Annual Meeting of the Law and Society Association (LSA) and the Research Committee on Sociology of Law (RCSL)., Berlim, 25 a 28 de Julho de 2007.

TORRES, Ricardo Lobo. Direitos fundamentai. In: BARRETTO, Vicente de Paulo. Dicionário de filosofia do direito. São Leopoldo: Unisinos, 2006.

TORRES, Ricardo Lobo. O direito ao mínimo existencial. Rio de Janeiro: Renovar, 2009.

VENEZUELA. Constitución de la República Bolivariana de Venezuela. Disponível em: <http:// www.constitucion.ve/documentos/ConstitucionRBV1999-ES.pdf>. Acesso em: 01 abr. 2001. 